\title{
The History and Sociology of Computer Science and Technology II.
}

\author{
Camille Akmut
}

January 25, 2022

\begin{abstract}
A second historiography series is started with the goal of producing an irreverent, hopefully useful review of available references. We call this new, stimulating field the history and sociology of computer science and, (therefrom derived), technology but do not forget the historical if not current role of philosophy.
\end{abstract}




\section{MONOGRAPHS}

- Heidegger, Martin. Holzwege / "The Question Concerning Technology", in English.

Lederhosen and Stoffhut ready, Heidegger manages to do both less than Marx ("technology cannot be destroyed") and Plato (his societal ideal of a philosopher king), leaving the contemporary researcher to contemplate what all the excitement was about. In his essay on Nietzsche, H. goes hardcore bucolic "Before the plowing comes the sowing" by which he means that the philosopher is the plower/slash/designer of knowledge, leaving to the dirty peasants of the city (mathematicians, social scientists, etc.) the successive task of sowing their "fields", with their little facts... One can, however, derive why the black boots might have enjoyed this. I can already hear the birds singing, and the crystal river water flowing.

- Davis, Martin. 1958. Computability and Unsolvability

Classic textbook produced and used during the infancy of computer science, for the corresponding (traditionally upper level) class - including by a young Donald Knuth.

- Davis, Martin. Var.. The Universal Computer / Engines of Logic [paperback]

The other book by Davis : a fairly straightforward history from Leibniz to Turing (Pascal was never forgiven his religious tendencies).

- Galloway, Alexander. 1994. Protocol: How Control Exists After Decentralization.

In a highly uncertain scholarly market, this work appears to be a serious attempt at a technologically-informed philosophy of technology.

\section{PAPERS}

— NBER. "Blockchain Analysis of the Bitcoin Market". nber . org/papers/w29396

Among their findings are iconoclast statements such as :

"90\% of transaction volume on the Bitcoin blockchain is not tied to economically meaningful activities", and furthermore " $0.1 \%$ (about 50 miners) control close to $50 \%$ of mining capacity"; essentially breaking with the long suspect myth of cryptocurrencies, as in the case of Bitcoin, bringing any "disruption" let alone "revolution" of banking. In fact, the image that emerges from this research is that such financial technologies reproduce the well known, well established, long studied inequalities and concentrations of wealth and power already found in the old world.

\section{POP CULTURE : FILMS, NOVELS...}

\section{Sense8}

An underrated National Geographics episode ("From Kenya to Reykjavik").

- Matrix 4 (2021)

Everyone is a black lesbian resistance fighter, the baddies are white men (what else!), robots are actually cool (cybebe), and the fascists are smashed, and a rainbow shines at the end. Gosh, this is grand cinema. Forget Vigo, folks.

- Attack surface (2020)

Girlboss Karen, Frances Haugen, Elizabeth Holmes Masha made some serious $\$ \$ \$$ (at not Google) but now has regrets. Oh, no... Vague anticommunism meets hollow Bush critique meets all the liberal tropes of the middle-aged liberal. Actually, it was her husband's fault - which will be the next installment in the series. 
- Wings of Honneamise (1987)

"Just speak in the vernacular, be yourself!" In this alternate universe (with distinct number-measurement system), space becomes available to humanity, but benevolent exploration and military and political exploitation soon become intertwined. Compatible with a Marxist view, the new technologies of this society lead to both personal tragedy (the destruction of a house for the benefit of energy production?) and social instability and labor fights. The movie that put Gainax on the map (see also "Otaku no video" for the phenomenon of extreme isolation of youths within capitalism, gathered around specific hobbies e.g. videos, war, pornography etc., themselves fairly commercial.)

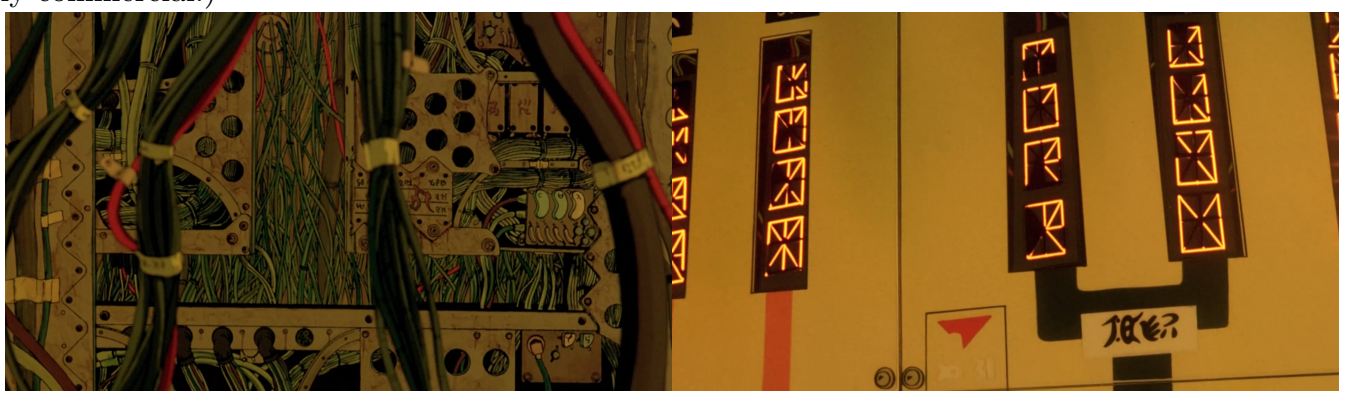

- Good Will Hunting (1997)

The famous problem is from graph theory (one of the few areas of mathematics where a non-expert could somewhat realistically make contributions due to its intuitive nature), and appears to be a typical homomorphism problem, with extra conditions added to it (but essentially, the background question remains, "are these the same?")

- Lee, Spike. 2021. The Currency of Currency. Ad for CoinCloud.

Cryptocurrencies are "inclusive", "fluid", "culturally rich" and inherently blackbrown and female (implied).

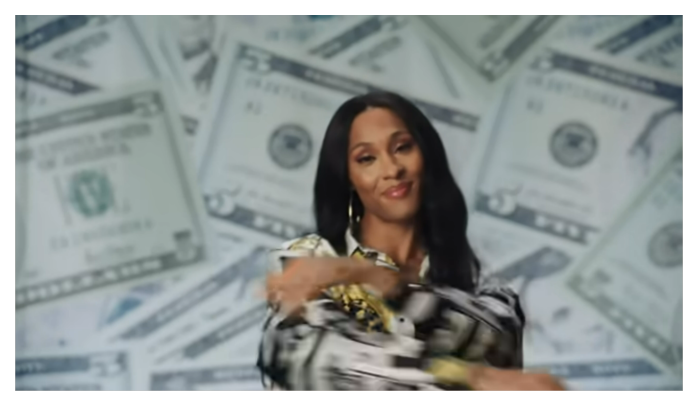

Figure 1: Black capitalism (variant).

\section{GENERAL SOCIAL SCIENCE}

- Frazier, Franklin. Black Bourgeoisie.

"[I]t was not until after Emancipation that the spirit of modem business enterprise really took root among the Negro elite. Frazier highlights the early, formative experiences around the Freedmen's Bank - which failed, but led way to many, new 
experiments, mostly banking projects in the "cities of the South" [ch. 1 The roots of the black bourgeoisie]. Ends with an absolute condemnation :

The black bourgeoisie suffers from "nothingness" because when Negroes attain middle-class status, their lives generally lose both content and significance.

- Reed, Adolph. 2021. "Why Black Lives Matter Can't be Co-opted". Nonsite, 23/07

BLM can't be recuperated : Behind this clever title, on which everyone at least will agree, lies nonetheless the inconvenient truth that something that has no substance cannot be recuperated... ["nominally left, but who can tell what that means anymore?"]

\section{NEWSPAPER ARTICLES}

— "Architect behind Googleplex now says it's dangerous...", NPR $22 / 01$.

The architect of Google's headquarters says it is dangerous because it blurs the line between work and non-work time, binding workers for as long as possible by offering them various on site services (the limit of which being the capitalist's ultimate dream of a worker available $24 / 7$, or total surplus value extraction).

- "Former Google CEO invests in computing help for university scientists. Schmidt Futures philanthropy launches [blabla]" Science, $18 / 01$.

Here, "homemade computer software written by students and postdocs" (read : community, free software) is opposed to "robust, flexible, and scalable software" (corporatecontrolled open source, cloud...).

OK, thanks Schmidt. This is definitely subtle reporting, and not advertisement at all, because not only is the journalist qualified but is also not adverse to risk taking and a hard-boiled life.

— "Le pillage de la communaute des logiciels libres" [The pillaging of the free software community]. Le Monde Diplomatique, January issue.

Published, in the tradition of free culture, as a paywalled article :

Mgr. Zacchiroli, who, in addition to having been a Director of the Open Source Initiative (i.e. the main think tank historically responsible for the dilution and even dismantlement of the original free software principles) also was one of the principal signatories of a letter calling for the social death of the founder of free software, now earnestly wonders why free software is weak and was co-opted or recuperated. Were some too power hungry, or is that businesses were too powerful, or perhaps an unlucky convergence of both?

Such is the tragedy of Monsieur Zacchiroli : yesterday far away, long forgotten, his repeated errors in judgment bring him eternal source material for new "research", and prompt thought pieces in the local press... 
Glenn Greenwald * Dec 23, 2021 ‥

Hillary Clinton has gone on a rampage warning about the severe dangers of Bitcoin to the hegemony of western institutions, US military power, and the global order. Say what you want about Hillary: the one thing she's never been is stupid. Worth thinking about why she so fears it.

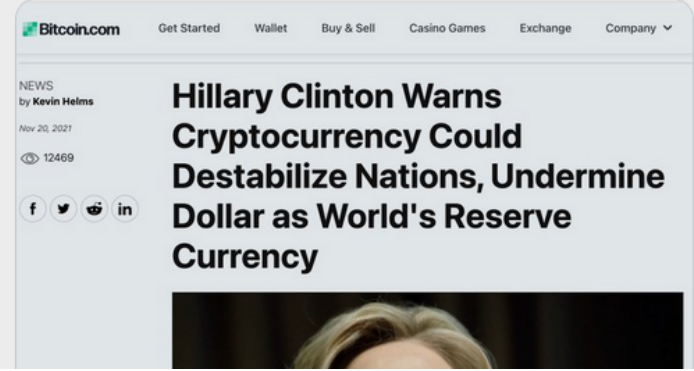

Figure 2: Glenn Greenwald during his "crypto" period. 